\title{
LINKING MENTAL AND PRIMARY HEALTH CARE IN RURAL AREAS
}

\author{
Mary P. Van Hook, Ph.D. and Marvella Ford, Ph.D.
}

There has been growing recognition in both developing and industrialized countries of the need to integrate mental and primary health care services in order to provide better care for community members and make the most effective use of scarce community resources (Pincus, 1987; Schulberg, 1991; World Health Organization, 1990). The impetus for creating these models comes from the growing recognition of the ongoing interplay between mental and physical health problems (Katon, VonKorff, Lin, Lipscomb, Russo, Wagner, \& Polk, 1990); the need for improved communication between mental health and primary care providers

Mary Van Hook is with the University of Michigan School of Social Work, and Marvella Ford is with the Center for Health Systems Studies, Henry Ford Health System, Detroit.

This project was sponsored by funds from the University of Michigan, Office of the Vice President for Research. An earlier version of this paper was presented at the National Association of Rural Mental Health, June 1993, Lincoln, NE.

Address for correspondence: Mary P. Van Hook, Ph.D., University of Michigan, School of Social Work, 1065 Frieze Bldg., Ann Arbor, MI 48109-1285.
(Kelleher, 1993; National Association of Rural Mental Health, 1993); and the vital role played by primary care providers in identifying, referring, and supplying ongoing care for persons with mental health difficulties (Schulberg, 1991; U.S. Congress, Office of Technical Assistance, 1990). Mental health difficulties, however, frequently go unidentified by the primary health care system. Primary care providers face special problems in assessing mental health difficulties because the mental health problems presented to them tend to assume somatic forms. Consequently, people with mental health problems often fail to receive appropriate treatment, are subject to needless tests and procedures, and consume an undue proportion of the limited resources of the primary care system (Barrett, Gerber, Barrett, Oxman, 1992; Attkisson \& Zich, 1990; Katon et al., 1990; Coyne, Schwenk, \& Fechner-Bates, 1991).

The barriers to providing health and mental health services in rural areas make it especially crucial to find ways to link mental health and primary health care (U.S. Congress, Office of Technical Assistance, 1990; National Advisory Committee on Rural 
Health, 1991). This paper addresses some of the issues pertaining to a specific linkage model that places rural mental health staff within primary care settings. The model has demonstrated promise in rural and other community settings (Pincus, 1987; Coulam, Hargrove, Geismar, \& Lentner, 1990; Marks \& Broskowski, 1981; Mueller \& Williams, 1985; Wertlieg, 1981; U.S. Congress, 1990). Primary care settings in this discussion include community based medical settings such as offices of family and general practitioners, community hospitals, and public health clinics which provide a range of ongoing care. This paper describes the context of the important policy and service delivery environment influencing the nature of mental and primary health services and potential linkages in rural areas. Since instituting programs can require a major investment in limited agency resources, the discussion highlights strategies used to maintain this arrangement.

\section{RURAL MENTAL AND PRIMARY HEALTH SYSTEM BARRIERS}

Rural health delivery systems and community characteristics impede the provision of adequate mental and primary health services in rural areas. Rural primary care physicians are in short supply and yet are likely to provide significant amounts of mental health care (Berger \& Dixon, 1990; Jones \& Parlour, 1985; U.S. Congress, 1990; U.S. Health Resources and Services Administration, 1990). Rural mental health services are narrower in scope and more limited than services in more urban areas. These rural services also tend to be very dependent on federal dollars. Lack of alternatives to the public mental health system in rural areas means that mandates to limit mental health services to the seriously mentally ill reduce broad community services (U.S. Congress, 1990). Rural mental health centers often find it difficult to respond to these challenges with new ways of delivering services (Mermelstein \& Sundet, 1988). The situation is fur- ther compounded by rural cultural codes stigmatizing the use of mental health services, lack of awareness of the existence and value of mental health services, problems of access due to the large geographic distances and lack of public transportation, an inadequate population base to support specialized programs, high poverty and dependency ratios, and large numbers of persons without adequate medical insurance (Berger \& Dixon, 1990; Coulam, Hargrove, Geismar, \& Lentner, 1990; U.S. Congress, 1990; U.S. Health Resources and Services Administration, 1990). Recent economic restructuring in rural areas has increased dependency ratios and reduced community resources to fund programs (Berger \& Dixon, 1990; Tickamyer \& Duncan, 1990).

\section{MENTAL HEALTH POLICY AND LINKAGE ARRANGEMENTS}

From 1978-1981, community mental health center funding policies encouraged collaborative efforts between mental health and other community services. This encouragement, however, ended with The Omnibus Budget Reconciliation Act of 1981 which repealed requirements for collaboration and subsequent legislation which severely curtailed rural mental health funding. The dependence of rural mental health systems on federal funds makes them especially vulnerable to policies that do not support education, prevention, and linkage services which do not produce billable hours (U.S. Congress, 1991).

\section{PRIOR RESEARCH ON LINKAGE ARRANGEMENTS}

Arrangements linking mental and general health care have been helpful in addressing some of the major problems in rural mental health care by improving detection of mental health problems by primary care providers, facilitating more appropriate utilization of both health and mental health services, in- 
creasing access to mental health services (especially for hard to reach populations such as elderly persons, minorities, and the poor), reducing the burden on primary care staff, improving the flow of information between service providers, decreasing stigma, providing better continuity of care, and drawing attention to the psychosocial stresses associated with health (Burns, Burke, Ozarin, 1983; Coulam, Hargrove, Geismar, \& Lentner, 1990; Johnson, 1991; Marks \& Broskowski, 1981; Mueller \& Williams, 1985; Parlor, Young, Jones, \& Brady, 1985; Wertlieg, 1981; U.S. Congress, 1990). Rural mental health centers established joint arrangements from 1978-1981 primarily to improve and expand their direct treatment and consultation services (Burns et al., 1983). Linkage arrangements involving inter-organizational efforts at the direct practice level seem particularly effective in accomplishing this goal (Marks \& Broskowski, 1981).

The linkage arrangement in this study involves aspects of inter-organizational coordination and interdisciplinary efforts. The literature in these areas suggests specific conditions that facilitate and threaten collaboration between organizations generally as well as linkages between mental and physical health specifically. The following conditions appear to encourage successful collaboration between organizations: agreement by the parties involved regarding the existence of a problem and cooperation as a viable solution, timing that places this problem as a high priority, involvement of parties with control over resources, leadership that is open to new solutions, beliefs that everyone will benefit by the arrangement, commitment to ongoing communication to solve the problems that will arise, recognition of the limitations of the program, a relationship of trust and understanding between the parties, a history of successful joint efforts, an external environment that lacks adequate resources and supports linkage arrangements, reciprocal planning in the development of the arrangement, and clear delineation of arrangements (Beatrice, 1990; Marks \&
Broskowski, 1981; Wimpfheimer, Bloom, \& Kramer, 1990; Gummer, 1990). Barriers to inter-organization cooperation include differences between the parties regarding procedures, priorities, implementation of policy, and cultures and changes within the external environment which undermine the arrangements (Beatrice, 1990).

Barriers to cooperation between mental health and primary providers specifically include: problems in billing for linkage services, fear of autonomy in decision making, lack of trust regarding the professional competence of mental health staff by primary health care system, problems of recruitment, tensions created by differences in the orientations of the disciplines involved, isolation of mental health staff, different ways of carrying out mental and primary and health services, and logistical problems of transportation, records, and space (Burns et al., 1983; Marks \& Broskowski, 1981; Mueller \& Williams, 1985; Wertlieg, 1981). Linkage staff and administrators of rural centers often differ in their perceptions of problems with linkage staff more likely to report problems relating to lack of clarity regarding their responsibilities and the program (Burns et al., 1983). The vital importance of the primary care providers' view of the competence of the mental health center staff received support from the results of a recent shortterm linkage program (1988-1989) designed to reach out to distressed farm families during the farm crisis. Initial perceptions of competency proved difficult to alter (Coulam et al., 1990; Johnson, 1991).

Interdisciplinary efforts are generally facilitated by the value of the concept of a "whole person," organizational structures that clearly delineate communication patterns and authority, and external mandates for accountability. Barriers to effective team efforts include differing professional perspectives, lack of respect for the contribution of the other disciplines, ineffective communication, lack of common goals, and unclear role definitions (Leukefeld \& Battjes, 1989).

Program viability is further linked with perceptions that a program is core to the 
organization as a whole (Singh \& Lumsden, 1990).

\section{STUDY PURPOSE AND DESIGN}

In view of major policy changes that have narrowed the scope of mental health services and reduced the incentives for linkage arrangements, as well as the problems facing rural mental and primary health care systems, a study was conducted to identify the benefits and challenges to implementing a linkage model placing staff of mental health centers in rural community health care settings.

\section{Sample}

Respondents included administrators of mental and primary health centers, engaged currently or in the past five years with this linkage arrangement, that serve rural areas in four Midwestern farm-belt states: Illinois, Iowa, Michigan, and Nebraska. The administrators of mental health centers listed with the departments of mental health in these states were asked by letter if staff members were currently located in a primary medical setting or had been placed there within the past five years. The response rate to this letter was $89 \%$ with $33(31 \%)$ indicating having this arrangement currently, another $14(9 \%)$ having had it during the past five years but discontinuing it, and $57(60 \%)$ not having been involved in this arrangement during the past five years. Primary care provider respondents were the primary care settings where these mental health centers had staff located.

\section{Methodology}

A letter and accompanying questionnaire were sent to the director or relevant staff person within each mental health center included in the study. The letter explained that the questionnaire was to be used as a guide for a subsequent telephone interview. A similar questionnaire with the questions asked from the perspective of the primary care providers was subsequently sent to the primary care providers but was not followed up with a telephone interview.

The questionnaire was designed to obtain information about the following aspects of the linkage arrangement:

- The nature of the arrangement, including the types of primary care sites used, mental health disciplines placed in these sites, aspects of the programs linked, the duration of the arrangement, and the perceived degree of centrality of the arrangement to the mission of the mental health center;

- The process of initiating the linkage arrangement, including the parties involved and the rationale;

- The impact of the linkage arrangement on referrals and services;

- The problems encountered and strategies developed to address these problems.

Telephone interviews were conducted with 32 administrators representing 39 programs currently involved in linkages (a $96 \%$ response rate). Response rate from those who discontinued the program was $38 \%, N$ $=6$ (five had discontinued the program prior to five years and current staff did not have adequate information; three administrators were difficult to contact). The response from the primary care providers was markedly lower $(50 \%, 16$ centers replied but only 13 questionnaires were appropriate for the study). Since most of respondents were engaged in ongoing linkage programs, data reported in this study focus primarily on the characteristics, benefits, problems, and strategies related to these programs. Problems leading to the demise of the six projects are discussed.

\section{Findings}

\footnotetext{
Description of the current linkage programs

Location. Mental health centers reported that the most commonly used site was a community hospital ( $N=26,66.6 \%$ ), followed by the public health department $(N=7$,
} 
$17.9 \%)$, primary care clinics $(\mathrm{N}=4$, $10.2 \%$ ), and single arrangements at nursing homes, prenatal clinics, and comprehensive health centers $(5 \%)$.

Rationale for selecting the sile. Mental health centers reported a similar rationale for site selection. These reasons included improving access to mental health services, making the most of limited mental health financial resources, improving the credibility and reducing the stigma of mental health services, recognizing the inherent mental/physical health linkages, and giving mental health staff needed medical backup. The community hospital provided the added benefits of the emergency room, 24-hour access, and improved security for mental health staff. Respondents generally reported that they would choose the site for the arrangement again. No differences in degree of satisfaction with the site emerged across the various settings.

Sharing of facilities. Most arrangements shared only physical space $(\mathrm{N}=19,49 \%)$, while fewer shared office space $(N=12$, $30.7 \%)$, or had joint records $(N=8$, $20.5 \%$ ).

Mental health disciplines placed. Mental health centers reported that personnel from several mental health disciplines predominated the staff in these linkage arrangements: social workers, $\mathrm{N}=26,66.7 \%$; psychologists, $\mathbf{N}=25,64 \%$; psychiatrists, $\mathrm{N}$ $=20,51 \%$; registered nurses, $N=18$, $48.7 \%$; and others, $\mathrm{N}=14,35.8 \%$.

Roles of specific mental health staff. Mental health and primary care providers agreed generally in this area. Social workers completed evaluations and direct treatment. Special advantages of social workers included their family systems approach, similarity in training and outlook with the social services department of the hospital, ability to coordinate care, and affordable cost.

Psychiatrists provided evaluations, medical treatment, and supervision of staff. They were also needed to provide medicine for the chronic mentally ill and were required in one state for an agency to maintain state certification. Unfortunately, psychiatrists tended to be expensive, which limited the number of hours that the centers could employ them.

Psychologists performed assessments, direct treatment, and implemented behavior plans in the nursing homes. Their advantages included excellent training in mental health and credibility within the medical community. The disadvantages associated with psychologists were their lack of ability to prescribe medication and the high cost of their services.

Registered nurses provided evaluations, medical management in conjunction with physicians, and crisis and general counseling. While less expensive to employ than psychiatrists, they tended to be difficult to recruit and had a high turn-over rate.

In terms of other disciplines, trained mental health counselors were reported to be less expensive to employ than M.S.W. social workers and were effective in assessment and counseling but were frequently ineligible for third party reimbursement. Substance abuse counselors were helpful in supplementing generalist practitioners.

Centrality of the linkage arrangement. Mental health centers typically viewed this arrangement as extremely central to their mission. On a scale from 1 (not central) to 5 (very central) arrangements at all sites received high ratings: community hospital received a mean of 4.1 ; public health department, 4.83 ; office of primary care physician 4.0, and other settings 4 . Differences between these scores were not significant. The centrality of this linkage arrangement is reflected in the efforts reported by administrators to sustain the arrangement.

Duration of the linkage arrangement. The majority of these arrangements had been in place for many years $(x=10.8$ years). Twenty sites $(51 \%)$ had maintained the linkage arrangement for 10 years and longer while $19(49 \%)$ had maintained this type of arrangement for less than 10 years. Length of time was not associated with the nature of the site, mental health disciplines involved, or the process of instituting the program.

Process of initiating the linkage arrangement. Administrators of mental health centers and 
of primary care centers had somewhat different perspectives regarding who took the leadership in establishing these programs. Almost one third $(30.7 \%, N=12)$ of mental health center administrators reported that mental health centers had originated the arrangement but none of the primary care centers reported this. On the other hand $23.2 \%$ $(\mathrm{N}=3)$ of primary care providers identified their programs as originating the arrangement while only $7.6 \%(\mathrm{~N}=3)$ did so. Both groups reported that many arrangements were initiated jointly (mental health$30.7 \%, N=12$, and primary care $-46.4 \%$, $\mathrm{N}=4$ ). Various other community groups and special projects were cited to a lesser extent.

What prompted placement of mental health staff in primary care. The primary reasons cited in rank order by both mental health and primary medical care administrators were to improve coordination, reduce barriers to service, address practical issues of office space and financial concerns, and respond to special projects and grants. Others reasons cited by several centers included decreasing costs, addressing other financial problems of mental health centers, improving security for mental health staff, increasing services to the community, and political reasons.

\section{Impact on services}

Referrals. Both mental and primary health providers reported that the linkage arrangement in all sites increased the numbers of referrals to mental health in general as well as those from the medical community resulting in clients with a broader range of presenting problems and issues. Improved accessibility and credibility made the referral process more efficient. Improved client acceptance of referrals for mental health was reflected in better follow up, less reluctance to use services, and decreased stigma about using services. While administrators reported that staff were initially concerned about confidentiality, there were mixed reports about the actual response of clients.

Community hospitals were further identified as enabling mental health staff to offer a wider range of services, provide better consultation for medical staff, and identify men- tal health aspects of physical problems. On a less positive note, mental health centers indicated that hospitals and the emergency rooms risked being inappropriately identified as "dumping centers" for persons with mental health and substance abuse problems.

Chief benefits of the joint arrangement. Mental and primary care respondents identified the primary benefits in terms of improved coordination, efficiency, accessibility, and acceptability of services. The ability to expand services was also important but a less frequent response. Financial reasons emerged as a very minor factor.

Problems encountered and strategies used. Mental and primary health centers reported obstacles to implementing these joint arrangements that echo problems cited in earlier studies. Differences in perspectives between mental and primary care staff and problems associated with space were the main problems cited. No pattern of association emerged between types of problems and either the site, the staffing, or ways in which the programs were begun.

(1) Differences in perspectives between mental and primary health were noted by $30.7 \%(\mathrm{~N}=12)$ of the mental health administrators and $54.5 \%(\mathrm{~N}=5)$ of the primary medical administrators. Differences in perspectives not only posed problems but were also cited as a benefit of the linkage arrangement. These differences were addressed primarily by establishing avenues for ongoing dialogue between mental and primary health care staff, such as individual meetings between representatives of the disciplines, attendance by mental health staff at physicians meetings, case staffing involving mental and physical health staff, use of a team approach with clients, placement of mental health staff on the boards of primary care facilities and vice versa, and joint social activities for mental and primary health staff. While mental health staff sought to present alternatives to the medical model, primary care providers saw the need to educate mental health staff in dealing with the fast paced world of primary care. As stated by one primary care provider, "linking mental and primary 
health requires substantial dialogue prior to the decision and commitment to ongoing communication about problems as they arise."

(2) Space problems were identified by $25.6 \%(\mathrm{~N}=12)$ of the mental health administrators and $36 \%(N=4)$ of the primary health sites. Addressing the problem of lack of space required ongoing requests from mental health providers for more space. A few primary care centers were described as building extra rooms for mental health center activities. Space represented the major reason why the centers that had discontinued the arrangement did so.

(3) Inappropriate referrals for mental health care were considered a problem by $23 \%(N=9)$ of the mental health center administrators and by $15 \%(N=2)$ of the primary care center directors. Mental health staff reported ongoing efforts to educate medical staff and other community agencies about the types of services they provided and the nature of persons they could help. Both mental and primary health administrators tried to educate the community to correct misconceptions contributing to the hospital emergency room being used as a "dumping ground" for persons with mental health problems. Referrals were also made to more appropriate settings.

(4) Costs were identified as a problem by $23 \%(\mathrm{~N}=9)$ of the mental health centers and by $36 \%(\mathrm{~N}=4)$ of the administrators of primary care settings. Strategies to deal with the costs of the linkage involved finding ways to bill appropriately for mental health services, expanding the availability of funds for services by convincing the community of the value of this manner of service delivery, making the linkage arrangement more visible in the community, and sharing staff between mental and primary care.

(5) Isolation of mental health staff was cited only by the mental health center administrators $(20.5 \%, \mathrm{~N}=8)$. The mental health centers addressed this issue through ongoing meetings between staff located in the medical facilities and those at the central office, rotating staff through the medical set- tings, providing ongoing briefing of mental health staff located in satellites, and conveying information from the satellites to the main programs. Satellite staff also established groups involving mental health and other health programs in their areas. The importance of addressing isolation is supported by prior research indicating that professional isolation is a major source of stress for rural human service workers (Sundet \& Cowger, 1990).

(6) Staffing shortages were cited by $17.9 \%$ $(\mathrm{N}=7)$ of the mental health center administrators and by $7.6 \%(N=1)$ of the primary care site administrators. The increased referrals generated by the linkage arrangement required additional staff and administrative efforts to seek funds for more staff. Recruitment was also paired with screening prior to hiring staff regarding the conditions of the work and efforts to find staff willing to carry out wide-ranging responsibilities.

(7) Administrative-logistical problems were cited only by the mental health center administrators $(20.5 \%, N=8)$. Maintaining these joint arrangements required ongoing communication through committees (including hospital committees) and with the medical administrators. It also meant training staff in safety, collection of fees, and the special requirements of the satellite program.

(8) General problems of getting along between mental health and primary care were noted by $15.3 \%(N=6)$ of the administrators of mental health centers and by $27.2 \%$ $(\mathrm{N}=3)$ of primary care centers. Agencies sought to hire staff with the ability to work with other disciplines and created joint training efforts involving mental health and primary care staff. Mental health centers engaged in ongoing efforts to promote education and dialogue with primary care staff through tasks forces, educating medical staff about mental health issues such as the nature of a psychiatric emergency. Monthly meetings with medical staff in charge of important medical units were held to identify problems and work out solutions.

Plans to continue the arrangement. Virtually all 
respondents currently engaged in these joint arrangements planned to continue them primarily because they view them as effective and efficient ways to deliver services. Joining the limited resources of the two systems was viewed as a way to enable them to provide the community and their staff with better services.

Perspectives of programs discontinuing the program. The reasons for beginning the program, staffing patterns, and problems encountered were generally similar between programs presently in operation and those that had discontinued the arrangement. The differences occurred primarily in terms of the efforts invested by both mental health and primary care in the establishment and ongoing maintenance of the program. Administrators warned that these programs cannot be established as a way of saving money because they require extensive efforts to address logistical problems, space issues, and differences in perspectives between mental and physical health care. Environmental barriers involving closing of health care programs and policy changes also contributed to the discontinuance of three joint programs.

\section{CONCLUSIONS}

This study affirms the results of previous studies indicating that a joint arrangement between providers of mental and primary health is a potentially useful means of delivering mental health services, especially in areas where accessibility and credibility tend to be barriers to use. Several factors cited regarding linkage arrangements in general emerged as vital to the success of these programs: leadership that supports the program and is, consequently, willing to make efforts to maintain it; mutual interdependence between the agencies so that each benefits from the expertise and resources of the other program; lack of resources within the environment which encourages inter-agency cooperation; and ongoing exchange of information to address problems in different perspectives and to provide coordinated services. Successful past experiences encouraged persons to expend efforts to maintain such programs. These findings emphasize the need to address the barriers cited in other studies: distrust of professional competence, differences in orientations and ways of carrying out mental and primary health care services, space issues, and isolation of mental health staff. Establishing and maintaining successful linkage arrangements requires ongoing efforts to forge a common philosophy of service that transcends the differences between the parties involved. This requires allocation of time beyond "billable hours" for staff involved in these projects.

The perspectives represented in this study were limited to administrators and may not accurately reflect the views of the line staff or clients involved. Findings in previous studies revealed differences in the perspectives of administrators and line staff regarding these arrangements. The low response rate from primary care providers makes it more difficult to make generalizations about this group. Future studies could entail a more vigorous followup. Unfortunately, the number of respondents in this study did not permit a real comparison between programs that had discontinued the program and those that were engaged in ongoing programs. It would be useful to compare the results obtained in these rural Midwestern states with linkage arrangements in other rural or urban areas.

Creating the essential climate of trust between mental and primary health care providers requires members of mental health disciplines to understand the differences in training and orientation in the two systems and to be willing to engage in ongoing dialogue with primary care providers and the community as a whole. Social workers involved in primary care settings can serve an important liaison role in this process. These efforts can create a climate in which the contributions of the various disciplines and perspectives are valued. 


\section{REFERENCES}

Attkisson, C., \& Zich, J. (1990). Depression in primary care: Screening and delection. New York: Routledge.

Barrett, J., Gerber, P., Barrett, J., \& Oxman, T. (1992, October). The relationship of presenting complaints to depression in a rural primary care practice. Paper presented at the Sixth Annual NIMH/ International Research Conference on Primary Care Mental Health Research: Concepts, Methods, and Obstacles, Tysons Corner, VA.

Beatrice, D. (1990). Inter-agency coordination: A practitioner's guide to a strategy for effective social policy. Administration in Social Work, 14(4), 45-59.

Berger, G., \& Dixon, L. (1990). Mental health services in rural America: State Health Reports, 58. Washington, DC: George Washington University.

Burns, B., Burke, J., \& Ozarin, L. (1983). Linking health and mental health services in rural areas. International Journal of Mental Health, 12, 130-143.

Coulam, R., Hargrove, S., Geismar, M., \& Lentner, T. (1990). Evaluation of the NIMHFunded Rural Mental Health Demonstration Projects. Cambridge, MA: ABT Associates.

Coyne, J., Schwenk, T., \& Fechner-Bates, S. (1993, October). Nondetection of depression by family physicians reconsidered. Paper presented at the Sixth Annual NIMH International Research Conference on Primary Care Mental Health Research: Concepts, Methods, and Obstacles, Tysons Corner, VA.

Gummer, B. (1990). Current perspectives on inter-organizational relationship. Administration in Social Work, 14(4), 117-128.

Johnson, D. (1991). Alternative sites for delivery of rural mental health services: An examination of clients served in two demonstration projects. Lincoln, NE: Center for Rural Health Research.

Jones, L., \& Parlour, R. (1985). Psychiatric services for underserved rural populations. New York: Brunner/Mazel.

Katon, W., VanKorff, M., Lin, E., Lipscomb, P., Russo, J., Wagner, E., \& Polk. E. (1990). Distressed high users of medical care DSM IIIR-Diagnosis and treatment needs. General Hospital Psychialry, 12, 355-362.

Kelleher, K. (1993). Linking mental health and primary care. Lincoln, NE: National Association of Rural Mental Health.

Leukefeld, C., \& Battjes, R. (1989). Interprofessional collaboration. In M. Henk (Ed). Social work in primary care (pp. 145-159). Newbury Park: Sage.

Marks, E., \& Broskowski, A. (1981). Community mental health and organized health care link- ages. In A. Broskowski, E. Marks, \& S. Budman (Eds.), Linking health and mental health (pp. 159-182). Beverly Hills: Sage.

Mermelstein, J., \& Sundet, P. (1986) Rural community mental health centers' responses to the farm crisis. Human Services in the Rural Environment, 10(1) 21-26.

Mueller, T. \& Williams, D. (1985). The social worker in the family physician's office. In L.R. Jones \& R. Parlour (Eds), Psychialric services for underserved rural populations. New York: Brunner/ Mazel.

National Advisory Committee on Rural Health. (1991). Fourth annual report on rural health. Washington, DC: U.S. Department of Health and Human Services.

National Association of Rural Mental Health. (1993). Report of focus group of integration of mental and primary health care. Lincoln, NE: Author.

Parlour, R., Young, L., Jones, L., \& Brady, T. (1985). Linkage of health and mental health services. In L. R. Jones \& R. Parlour (Eds), Psychiatric services for underserved rural populations. New York: Brunner/Mazel.

Pincus, H. (1987). Patient-oriented models for linking primary care and mental health care. General Hospital Psychiatry, 9 126-134.

Schulberg, H. (1991). Mental disorders in the primary care setting: Research priorities for the 1990's. General Hospital Psychialry, 13, 156-164.

Singh, J., \& Lumdsen, C. (1990). Theory and research in organizational ecology. Annual $R \varepsilon^{-}$ view of Sociology, 16, 161-195.

Sundet, P., \& Cowger, C. (1990). The rural community environment as a stress factor for rural child welfare workers. Administration in Social Work, 14(3), 97-110.

Tickamyer, A., \& Duncan, C. (1990). Poverty and opportunity structure in rural America. $A n$ nual Review of Sociology, 16, 67-86.

U.S. Congress, Office of Technological Assessment. (1990). Health care in rural America. Washington, DC: U.S. Government Printing Office.

U.S. Health Resources and Services Administration. (1990). Rural health professions facts: Supply and distribution. Washington, DC: Author.

Wertlieg, D. (1981). Mental health providers in primary care settings. In A. Broskowski, E. Marks, \& S. Budman (Eds)., Linking health and mental health (pp. 115-136). Beverly Hills: Sage.

Wimptheimer, R., Bloom, M., \& Kramer, M. (1990). Inter-agency collaboration: Some working principles. Administration in Social Work, 14(4), 89-110.

World Health Organization. (1990). The introduction of a mental health component into primary health care. Geneva: Author. 